\title{
Opinión
}

\section{Consideraciones sobre el consentimiento del paciente en la prueba pericial médica}

\author{
(Considerations About Patient's Consent in Expert Evidence Evaluation)
}

\author{
Grettchen Flores-Sandí
}

\section{Resumen}

El objetivo de la actuación médica pericial es auxiliar a la jueces y tribunales sobre cualquier aspecto médico de una persona implicada en un proceso judicial, de forma que permita una correcta administración de la justicia. Independientemente del incidente denunciado, en el contexto clínico médico forense, el consentimiento o aceptación de la realización del peritaje por parte de la persona que será valorada, implica aspectos éticos, de información, y elementos particulares periciales que deben ser considerados por el médico evaluador, para que su labor cumpla con el requerimiento legal.

Descriptores: Consentimiento del paciente, perito médico, bioética.

\begin{abstract}
The aim of the expert medical evaluation is to collaborate with judges and court in the evaluation of medical aspects of a person undergoing a judicial process, in order to facilitate reaching a correct justice administration. Regardless of the reported incident, in the context of clinical forensic medicine, the patient's consent has some ethical, informative and particular aspects to be considered by the medical expert, in order to full fill the legal requirements.
\end{abstract}

Keywords: patient's consent, medical expertise, bioethics

Recibido: 2 de setiembre de 2010

Aceptado: 9 de noviembre de 2010

La prueba pericial médica es el dictamen que realiza un médico sobre cualquier aspecto técnico, con el propósito de que un juez pueda conocer mejor aspectos médicos de una

Departamento Medicina Legal

Ciudad Judicial, San Joaquín de Flores

Correspondencia

Correo electrónico: grettchenflores@medicos.cr

ISSN 0001-6002/2011/53/1/26-29

Acta Médica Costarricense, (O2011

Colegio de Médicos y Cirujanos persona en un procedimiento judicial. Existen dos clases de prueba pericial, según a quien se solicite: la prueba pericial aportada por las partes y la efectuada por un perito nombrado por el órgano jurisdiccional. ${ }^{1}$

Las partes, el fiscal o el propio juez pueden recurrir a este tipo de prueba. La clave de la cuestión es que la persona que debe decidir (juez) carece de la formación necesaria para valorar y tiene que guiarse por lo que informa el médico, ${ }^{2}$ de lo que se desprende que una pericia negligente puede provocar una resolución equivocada. ${ }^{3}$

La actuación del perito médico debe aunar los principios legales y morales vigentes para que la misión que ostenta sea conforme a las reglas del buen arte profesional, tomando en cuenta las peculiaridades de la actividad pericial ${ }^{3,4}$ (Cuadro 1). Así, en el concepto de peritaje médico confluyen la perspectiva médica y la jurídica, ${ }^{5}$ pues a un tercero se le trasladan información y hallazgos médicos de una persona.

Por lo tanto, este acto precisa un consentimiento o autorización de la persona por peritar, apoyado en materia penal en el Art. 36 de la Constitución Política de Costa Rica, que establece el derecho de abstenerse de declarar contra sí mismo y contra parientes, cuando la persona sea sujeto de prueba. $^{6}$

Es así que la regulación y aplicación, tanto del secreto médico como del consentimiento del paciente, en el ámbito de la actuación médica pericial, contempla conflictos y dificultades importantes e implica aspectos bioéticos y de información.

\section{Deontología y utilización de datos personales}

En este contexto, debe tenerse presente que el perito, como médico que es, está formado para relacionarse con un ser humano que requiere un trato digno y respeto a sus derechos como paciente. El respeto por los valores $\mathrm{y}$ aspiraciones de las personas es un deber que cobra mayor importancia si la persona es vulnerable. Debido a que la autonomía y la responsabilidad de las personas, incluidas aquellas que requieren atención médica, se aceptan como valores fundamentales, la participación de cada individuo en 


\title{
Cuadro 1. Peculiaridades de la actividad pericial médica
}

\begin{tabular}{|ll|}
\hline \multicolumn{1}{|c|}{ Aspectos } & Características \\
\hline Objetivo & No es atender a un paciente, sino determinar la verdad sobre un problema legal. \\
& El perito no integra una relación simétrica, como es o debería ser la relación médico-paciente, \\
Relación con paciente & $\begin{array}{l}\text { sino que establece una relación asimétrica, perito-persona por peritar. Salvo oportunidades } \\
\text { extraordinarias, la labor pericial médica se establece sin que la persona sujeto de la peritación } \\
\text { pueda, en absoluto, elegir o disponer quién será el perito que lo evaluará. }\end{array}$ \\
& $\begin{array}{l}\text { Una vez realizada la historia médico legal, con base en la documentación médica o la } \\
\text { exploración pertinente, los datos clínicos son sometidos al concepto general del secreto } \\
\text { profesional, pero además deben de ser "traducidos" con el propósito de que sean utilizados } \\
\text { para la administración de justicia. }\end{array}$ \\
\hline
\end{tabular}

\section{Cuadro 2. Supuestos del proceso de consentimiento}

\author{
Consentimiento \\ (Voluntad convergente o coincidente de dos partes)
}

Para el paciente:

- Mayoría de edad y que no esté privado de razón.

- Prestado voluntaria, consciente y libremente.

- La decisión no debe ser tomada por el médico en lugar suyo.
Para el profesional:

- Proveer adecuada información al paciente, de manera que pueda participar inteligentemente en la toma de una decisión.

- Imposibilidad de actuar sin recabar el consentimiento de la persona.

- Totalmente ineficaz en intervenciones ilícitas. las decisiones sobre su cuerpo y su salud deben reconocerse universalmente también como un derecho de las personas. ${ }^{4,7}$ Al respecto, el Código de Ética Médica vigente en Costa Rica, ${ }^{8}$ en su Art. 113 establece que el médico llamado a actuar como perito, deberá dirigirse con objetividad y dentro de los límites de sus atribuciones y competencia, y antes de examinar al paciente, debe informarle que su función es de experto y que, como tal, tiene que rendir su informe de perito, absteniéndose de hacer comentarios subjetivos.

Los profundos cambios acontecidos en la relación médico-paciente, vinculados particularmente con una mayor autonomía de este último, como consecuencia y expresión de su dignidad, han determinado el desarrollo del concepto de "consentimiento informado", definido como la conformidad libre, voluntaria y consciente del paciente, manifestada en el pleno uso de sus facultades, después de recibir la información adecuada, para que tenga lugar una actuación que afecta su salud. Esta información debe ser previa y contener las consecuencias más relevantes de la intervención, los riesgos asociados con esta y las contraindicaciones, dejando claros dos puntos: la adecuación de la información y la obligatoriedad de contar con el consentimiento del paciente. ${ }^{7,9}$
Es factible deducir que la actividad profesional como médicos peritos, se aleja de la definición del concepto de "consentimiento informado", toda vez que esta actividad no afectará su salud, no se le ofrecen opciones de tratamiento y no se pueden relatar las consecuencias más importantes, ni los riesgos relacionados $\mathrm{y}$, por supuesto, las contraindicaciones. Pero sí requiere un consentimiento, entendido como toda manifestación de voluntad, libre, inequívoca, específica e informada, mediante la que el interesado consiente el tratamiento de datos personales que le conciernen. En un peritaje no hay consentimiento informado, sino un mero consentimiento o aceptación para que se realice el peritaje, con todas las consecuencias que implica. A menos que la persona deba ingerir algo o someterse a cirugía por necesidad de la prueba, está exenta del "consentimiento informado". 5,6, 10,11

Se consideran datos médicos los referentes a la salud de una persona, ya sea pasada, presente o previsiblemente futura, o también los referidos a posibles adicciones del sujeto de valoración, también lo son los datos administrativos (nombre, teléfono o dirección) ubicados físicamente en las instituciones de salud, o que sin estar ahí, dependan de esta (pueden encontrarse alojados en un servidor situado en otro lugar, fuera de la consulta o clínica, pero controlado por esta). 
Con la elaboración del informe queda patente que el médico perito tendrá acceso a datos de la esfera íntima del paciente, la cual deberá salvaguardarse. El médico valorador tiene que omitir en su informe todo lo que no sea directamente relevante para el caso, es decir, limitarse a peritar lo sucedido. ${ }^{10}$

\section{Actuación pericial médica}

El paciente tiene derecho a conocer sobre lo que será objeto de pericia, su fin, los exámenes, análisis y estudios que se pretende realizar, así como sus efectos, riesgos y posibles complicaciones, explicando con todo detalle el alcance del estudio que se desea llevar a efecto, de manera que tenga en cuenta las circunstancias de la pericia, con un balance equilibrado de riesgos y beneficios legales. Además, es preciso que conozca si la pericia ha sido solicitada por un despacho judicial o por alguna entidad o persona física o jurídica distinta, así como la cualidad profesional del perito. ${ }^{9}$

Tras esta exhaustiva información, el interesado debe decidir voluntaria y libremente si acepta que se realice la pericia o, si se niega a esta (Cuadro 2). El consentimiento en estos casos se apoya en los principios básicos de autonomía de la voluntad y de libertad de todo paciente, y en que la información suministrada por el médico cumpla con ciertas premisas (Cuadro 3). ${ }^{9,} 12$

No obstante, existen problemas relativos a la pericia en relación con el consentimiento: ${ }^{4}$

a. Cuando el médico perito no es escogido por el paciente, sino que la valoración es solicitada por la autoridad judicial, ello no constituye obstáculo para dejar de cumplir la primera de las obligaciones, que es la de informarle de la misión encomendada $\mathrm{y}$ de quién proviene. También es la principal fuente de desacuerdo, por ser asumible la negativa del enfermo a ser examinado o a facilitar los datos médicos necesarios para efectuar el estudio de su caso. Por ello se requieren condiciones en el perito que permitan mantener un clima cálido con el paciente, siendo su primera función hacerle comprender que su actuación estará revestida de imparcialidad, ecuanimidad $\mathrm{y}$, en definitiva, que se comportará como un testigo experto al servicio del asunto, no al de las partes, por lo que no desempeña el papel de adversario.

b. El paciente tiene derecho a conocer que el propósito de una exploración médico pericial no es curar o aliviar una enfermedad, sino la administración de justicia, y que determinadas personas implicadas, conozcan adecuadamente su estado de salud. El paciente también debe saber que del informe del perito se derivarán consecuencias que pueden suponer la privación de la libertad para una persona, o bien, una indemnización económica considerable, o la concesión de una invalidez o una incapacidad laboral.

c. Generalmente, el consentimiento para la actuación pericial médica no suele ser formal en el sentido de ser expresado por escrito, tratándose de un consentimiento oral, tácito.

Resulta evidente la imposibilidad de ejecutar una pericia contra la voluntad de la persona afectada, siempre que para su realización sea preciso explorarle e, incluso, someterle a pruebas diagnósticas, pues de lo contrario podrían vulnerarse sus derechos fundamentales.

Situación distinta sería la pericia efectuada sobre la base exclusiva de documentación médica aportada por la autoridad judicial, en cuyo caso no se requeriría que el perito solicitase el consentimiento del interesado, toda vez que no lo explorará ni estudiará directamente, habiendo sido el juez quien le ha remitido los documentos e informes médicos con los que pretende que se lleve a efecto la pericia, con el fin de certificar extremos de interés para la resolución de un litigio.

La dificultad se presenta cuando el lesionado no presta su consentimiento ni para el acceso a su historial, ni para su exploración. En estas ocasiones el perito se encuentra en una situación de impedimento absoluto para ejercer la tarea encomendada.

\begin{tabular}{|c|c|}
\hline & Cuadro 3. Premisas de información para el paciente \\
\hline Premisas & Descripción \\
\hline Debe ser el perito quien informe directamente a la persona sobre la razón por la que \\
pretende realizar la pericia, siempre que sea mayor de edad y con plena capacidad mental. \\
Si se tratase de un menor o de un incapaz, la información se facilitara a sus representantes \\
legales. En todo caso, cuando se trata de menores de edad, debe dárseles también a ellos, \\
los datos adecuados a su capacidad natural de juicio y discernimiento. \\
Previa & Debe facilitarse antes de llevar a efecto la pericia, debiendo modularse a lo largo de esta. \\
Clara & Debe ser simple, aproximativa, leal e inteligible, es decir, en términos comprensibles.
\end{tabular}


En conclusión, y considerando que la actividad médico pericial es un acto médico encaminado a informar a un tercero, con la finalidad de que este pueda cuantificar los perjuicios sufridos en el patrimonio biológico de la persona, se debe recabar del paciente autorización para ceder sus datos, comunicándole el objeto del informe y la persona responsable, su uso y el destino del tratamiento de los datos, ya que estos datos son titularidad de la persona y su tratamiento requiere su consentimiento. Es indiscutible que no le corresponde al perito tomar decisiones por la persona ni insinuarle cuál debe ser su decisión, pues esto rozaría la ética, pero sí debe explicarle de qué se trata su trabajo, entendiendo que el fin de la actuación médica pericial debe ser el de aportar elementos veraces, que permitan a jueces y tribunales impartir justicia.

\section{Referencias:}

1. Fernández M. La prueba pericial. Medical Economics (Edición Española). 2006; 3: 22.

2. Flores G. El médico en procesos judiciales. Act Med Costarric 2008; 50: 47-50.

3. Ramos A. ¿Qué sería exigible al médico para realizar un peritaje profesional? Calidad y riesgo 2009. En: http://www.calidadyriesgo.es/ calidadasistencial/44-que-seria-exigible-al-medico-para-realizar-unperitaje-profesional. Consultado el 30 de julio de 2010.
4. Lachica E. El secreto médico y el consentimiento informado en los informes periciales. Cuad Med Forense 2002; 27: 29-37.

5. Laborda E. Cesión de datos o consentimiento informado en valoración del daño corporal. Conferencia presentada en el XV Congreso Nacional de Derecho Sanitario; 2008 oct 16; Ilustre Colegio Médico Oficial de Madrid, España; 2008. En: www.aeds.org/Congreso15/ docs/elc.doc. Consultado el 27 de agosto de 2010

6. Dall'anese F. Pericia médica y el derecho de abstención. Med Leg Costa Rica 2002; 19:59-66.

7. Sánchez AM. El consentimiento informado y la relación médicopaciente. Bioética 2009; 94-8

8. Colegio de Médicos y Cirujanos de Costa Rica. Código de Ética Médica. Diario Oficial La Gaceta. 2009; 130.

9. Galán JC. El consentimiento informado y la prueba pericial médica. Sideme 2001. En: http://www.sideme.org/doctrina/articulos/ art001212-es.htm. Consultado el 1 de agosto 2010.

10. Gómez D. El médico valorador ante el secreto médico y la protección de datos. Conferencia presentada en las II Jornadas sobre Secreto Médico y Protección de Datos en Valoración del Daño Corporal, organizadas por la Sociedad Española de Valoración del Daño Corporal; 2001 Oct 26; Madrid, España; 2001. En:http://www. protegemostusdatos.com/data/NOTICIAS/Microsoft $\% 20$ Word $\% 20$ -\%20Ponencia_Medico_Valorador_Secreto_Medico.pdf. Consultado el 4 de agosto de 2010.

11. Stark M. A Physician's Guide to Clinical Forensic Medicine. Totowa, New Jersey: Humana Press; 2000. p 21.

12. Kvitko. LA. El consentimiento informado y la pericia médico legal. Rev Latinoam de Derecho Médico y Medicina Legal 2003; 8: 77-80. 